\title{
RESENHA
}

\section{MURILO RUBIÃO — 20 ANOS DEPOIS DE SUA MORTE}

Referência da obra resenhada:

BATALHA, Cristina; GARCÍA, Flávio. (Org.). Murilo Rubião - 20 anos depois de sua morte. Rio de Janeiro: EdUERJ, 2013.

Mariana Silva Franzim ${ }^{1}$

Adelaide Caramuru Cezar ${ }^{2}$

O livro Murilo Rubião - 20 anos depois de sua morte é composto por sete ensaios e foi organizado porMaria Cristina Batalha e Flavio García, professores da UERJ. É resultante de evento ocorrido na Universidade Estadual do Rio de Janeiro entre 16 e 18 de novembro de 2011. Além dos sete ensaios, faz-se presenteno volume conto inédito do autor homenageado, "As unhas", publicado por Vera Lúcia Andrade e Ana Cristina Pimenta da Costa Val, em novembro de 1994 no Suplemento Literário de Minas Gerais. A divulgação do referido conto é acrescida de leitura crítico-interpretativa do mesmo efetivada por Prof. Dr. Flavio García. Trata-se do artigo de abertura da obra aqui resenhada:"Aspectos dos discursos fantásticos contemporâneos, pegados 'às unhas', em um conto 'não pronto para a publicação'.

O suporte teórico do qual o crítico se serviu para efetivação da leitura do conto rubiano foi artigo de Renato Prada Ortopeza, semioticista, professor, crítico literário, ficcionista e roteirista de cinema boliviano, publicado em 2006: El discurso fantástico contemporâneo: tensión semântica y efecto estético. O trabalho de Prada Ortopezaatém-se a três contos de autores hispano-americanos contemporâneos de Murilo Rubião: "La cena", de Al-

1 Mestranda no Programa de Pós-Graduação em Letras/Estudos Literários junto à Universidade Estadual de Lonfrina (UEL), Londrina, Paraná. Endereço eletrônico: marianafran zim@gmail.com.

2 Professor Associado C da Universidade Estadual de Lonfrina (UEL), Londrina, Paraná; doutorado em Letras pela Universidade Estadual Paulista Júlio de Mesquita Filho; integrante do GT da ANPOLL "Vertentes do insólito ficcional". Endereço eletrônico: accezar @uel.br. 
fonso Reyes, "El outro", de Jorge Luis Borges e "Casa tomada", de Julio Cortázar. Nestes contos, Prada Ortopeza destacaa ocorrência do insólito que emerge em clima de aparente normalidade, ou seja, construído numa realidade na qual tempo e espaço configuram-se de maneira sólita. Atém-se ainda Prof. Dr. Flavio Garcíaao insólitodefinido através de palavrasde Lenira Marques Covizzi emO insólito em Guimarães Rosa e Borges, onde a autora afirma que se trata do "não acreditável, incrível, desusado", ou seja, das "semioses negativas" que despertam no leitor "o sentimento do inverossímil, incômodo, infame, incongruente, impossível, infinito, incorrigível, incrível, inaudito" (COVIZZI, apud GARCIA, 2013, p. 22).

Uma vez apresentado o embasamento teórico, Flavio García registra que o conto rubiano "inicia-se de forma absolutamente sólita e previsível, em consonância com as experiências mais comuns que se tem da realidade cotidiana" (GARCIA, 2013, p. 19),facilitando, desta forma, a aproximação da realidade intratextual da extratextual por parte do leitor. Retoma Prada Oropeza quando este fala sobre o sem sentido inerente à estética deste modo narrativo, onde não há uma explicação reestabelecedora da ordem realista no discurso fantástico.No conto rubiano, tão insólito quanto o começo da doença, o crescimento excessivo das unhas, seu fim é anunciado de maneira estranha, uma vez que não vem acompanhada de nenhuma explicação, causando tanto assombro ao personagem quanto ao leitor. 0 insólito e a incerteza são pontos centrais destacados na análise empreendida por Flavio García,lembrando, ao término de sua leitura, que se trata de "eterna e permanente marca mais comum, própria e distintiva de todos os discursos fantásticos - clássicos ou contemporâneos - que conhecemos" (GARCÍA, 2013, p. 30).

Enquanto Flavio García atém-se a "leitura crítico-interpretativa" (GARCÍA, 2013, p. 16) de conto rubiano, Maria Cristina Batalha abre o leque e, em artigo intitulado "Murilo Rubião e o fantástico brasileiro moderno", situa o autor mineiro no contexto literário nacional, lembrando que sua obra se distancia "dos fantasmas e castelos mal assombrados" (BATALHA, 2013, p. 34) de nossos escritores do século XIX. A autora afirma que a literatura de Rubião, assim como a de Kafka, constituiuma modalidade do fantástico moderno denominado absurdo-existencial, pois, ao invés dos temas recorrentes no universo gótico como o sobrenatural, é a condição humana que figura no centro dessa categoria, com toda a crise moderna que envolve questões como desterritorialização, perda de valores e impotência. 
Profa. Dra. Maria Cristina Batalha afirma a existência de duas estratégias para criação do efeito de fantástico na obra muriliana. A primeira delasdiz respeito ao emprego da hipérbole e da proliferação. Demonstra tal estratégia nos contos "Bárbara", "Petúnia", "Aglaia" e "Teleco, o coelhinho". A segunda estratégia enfocada é "o tratamento da intriga, movida pela pura lógica do acontecimento, na qual o herói é impotente para inter- vir" (BATALHA, 2013, p. 36). Analisa tal estratégia em "O edifício", "O convidado", "Os comensais" e "Epidólia".A angústia moderna ligada à burocracia e à impessoalidade da vida urbana é destacada em dois contos: "A fila" e "A cidade". Outros contos são ainda enfocados em suas especificidades: "O pirotécnico Zacarias", "Alfredo", "O ex-mágico da Taberna Minhota".

$\mathrm{O}$ artigo termina com afirmação de Murilo Rubião a respeito dos pontos em comum entre sua obra e a de Kafka no que concerne a leituras comuns: a Bíblia, a mitologia, os contos do folclore alemão. Ainda que convirjam, conforme afirma o autor, a metamorfose não foi inventada por nenhum deles.

Como a dar continuidade ao artigo anterior, Marisa Martins GamaKhalil atém-se às metamorfoses rubianas ou murilianas em "A metamorfose do corpo e a construção do fantástico nas narrativas de Murilo Rubião". Tzvetan Todorov é logo lembrado por seu capítulo presente em Introdução à literaturafantástica: "Os temas do eu". Trata-se de ponto de partida para considerações a respeito das metamorfoses. Enquanto nos textos estudados pelo crítico búlgaroa metamorfose é construída como ruptura entre o corpo e o espírito, nos contos de Murilo Rubião, segundo Gama-Khalil,as metamorfoses fazem-se presente como experiências cotidianas, sendo impulsionadas pelo desejo."Bárbara" e "O homem do boné cinzento" são apresentados como exemplificação deste tipo de metamorfose involuntária e incontrolável.Em contrapartida, a autora ressalta que as metamorfoses de "Teleco, o coelhinho" podem parecer próximas do maravilhoso, uma vez que, numa primeira instância,fazem crer que sejam voluntárias e controla- das, quando, em verdade, são a manifestação do descontrole, uma vez queo real desejo do protagonista reside em tornar-se homem.

Marisa Gama-Khalilestuda os espaços presentes nos três contos analisados tomando como suporte a diferenciação oferecida por Deleuze e Guattarientre espaços lisoseespaços estriados, bem como entre espaços utópicos e heterotópicos, oferecidos por Michel Foucault. Não se atém apenas aos corpos dos personagens enquanto espaços, no caso, lisos e heterotópicos. Adentra-se no espaço do navio em "Bárbara", no espaço do hotel 
em "O homem do boné cinzento" e na constante modificação em busca de um fim nunca alcançado, melhor dizendo, apenas fragilmente alcançado em "Teleco, o coelhinho".

Todorov, que se fez presente no início do artigo, é retomado em sua conclusão. A hesitação, apresentada pelo estudioso húngaro como base da literatura fantástica, é substituída por posicionamento de Ítalo Calvino em "Definições de territórios: o fantástico", onde afirma: "a leitura da literatura fantástica implica outra coisa, 'uma tomada de distância, uma levitação, a aceitação de uma lógica outra que leva para objetos outros, diversos daqueles da experifncia diária'" (apud GAMA-KHALIL, 2013, p. 64-65).

Alcmeno Bastos, professor da Universidade Federal do Rio de Janeiro, é o autor do quarto artigo: "Murilo Rubião e a questão da causalidade". Atém-se inicialmente à verossimilhança, recorrendo à poética clássica, mais especificamente a Aristóteles. Também Boileau ocupa papel de destaque nas considerações teóricas. Ressalta que a inverossimilhança só foi admitida "nas formas 'menores' da ficção popular (nos contos de fadas, por exem- plo) ou nas formas 'elevadas', que recorriam ao acervo mitológico, especi- almente o greco-latino, como no caso da epopeia" (BASTOS, 2013, p. 68). A seguir, é o momento do enfoque da inverossimilhança nos séculos XIX e XX nos denominados realismos, sejam eles fantásticos, absurdos, mágicos...

Dedica-se o crítico ao enfoque da noção de causalidade como condição da verossimilhança, pois é ela, a causalidade, "que assegura ter havido lógica e racionalidade no encadeamento dos fatos" (BASTOS, 2013, p. 68). Aceita esta condição pelo leitor, Alcmeno Bastos rompe com sua certeza e afirma: "se todo verossímil está regrado pela causalidade, a recíproca não é verdadeira" (BASTOS, 2013, p. 69). Fala do problema da causalidade no maravilhoso puro, na narrativa realista, exemplificando suas colocações através do comportamento de Madame Bovary, de Capitu.

O passo seguinte consiste no enfoque do insólito nas narrativas dos denominados "realismos irrealistas" (BASTOS, 2013, p. 69). Kafka com sua Metamorfoseé logo citado, sendo seguido pela apresentação de Murilo Rubião como representante dessa corrente do insólito no Brasil. São apontados alguns exemplos da maneia como o narrador muriliano lida com a causalidade, atendo-se, aos contos "O edifício" e "A fila".

Todo este percursoevolutivo do conceito de verossimilhança e de sua ligação com a causalidade é então dirigido à análise de três contos do autor mineiro: "Mariazinha", "Os três nomes de Godofredo" e "Flor de vidro". Alcmeno Bastos muito logicamente vai conduzindo o raciocínio do leitor de 
um ponto a outro, culminando, ao final, em eficiente leitura dos citados três contos de maneira a restaurar as etapas vencidas.

O quinto texto, intitulado "Escrever é escrever de novo: a escrita infinita em Murilo Rubião" de Prof. Dr. Flávio Carneiro,crítico literário, roteirista e professor de Literatura Brasileira no Instituto de Letras da Universidade do Estado do Rio de Janeiro, trata da questão da reescritura na obra de Rubião. Carneiro escreve sobre os fantasmas de uma obra possível que não se realiza em detrimento de uma outra, resultado das escolhas finais do autor. Num primeiro momento, quando o próprio autor, antes da publicação, escreve, recorta, seleciona e reescreve o conto a ser publicado e quando, depois da publicação, se reapropria da obra e refaz o processo de criação, alterando e reescrevendo o texto para uma nova e alterada publicação que não muda o sentido geral da obra, modificando apenas pequenos detalhes.

O crítico aproxima a condição do autor à de seus personagens, ambos num refazer e numa reelaboração infinita e incessante. Aponta como exemplo Teleco, onde a aproximação é atestada na sua constante mudança de corpo, Alfredo e seu inconstante irmão e, por fim, o ex-mágico. 0 estudioso afirma um paralelo entre a metamorfose dos personagens e a reescritura do autor, ambos comprometidos coma busca pela compreensão e pela perfeita comunicabilidade. Carneiro afirma ainda quea escrita se faz infinita também por conta da leitura e das possibilidades de sentidos inseridos nesta. Atesta que a leitura é uma reescritura, onde cada leitor a cada leitura constrói um novo texto conferindo a esse novas significações e relações. Nesta relação, o leitor surgecomo garantia de eternidade. O crítico afirma que o autor e seus personagens (cita como exemplo Teleco, Alfredo, o exmágico, Bárbara e seu marido) assumem a figura de Sísifo, num fazer infinito e absurdo. Por mais que haja metamorfoses e reelaborações, todos continuarão sendo os mesmos e habitando o mesmo labirinto, não havendo evolução ou mudança de lugar.

Por fim fala do processo de criação como uma recriação daquilo que já está posto. Exemplifica como a criação de uma nova obra não é nada mais que a recriação de alguma outra que serve de base. Para isso, cita a presença da Bíblia e de Machado de Assis na obra de Rubião.Exemplifica através de paralelo entre Memórias Póstumas de Brás Cubas e Memórias do Contabilista Pedro Inácio, conto de autoria de Rubião. Para o crítico, tal movimento tem a função de eternizar e recriar a memória, configurando uma oposição ao ideal romântico e moderno de busca por originalidade. 
Todo esse movimento atesta o caráter de arquivista do autor. O crítico conclui que a reescritura aparece num movimento espiral: é ação do autor, dos personagens, do leitor e da própria literatura.

O sexto artigo presente na obra é de autoria do Prof. Dr. Hermenegildo Bastos, da Universidade Nacional de Brasília, e tem como título "Do insólito ao espectral em 'Ofelia, meu cachimbo e o mar'". A abertura do artigo dá-se de forma direta: "Praticamos uma crítica imanente, de modo que não nos acercamos da obra senão a partir daquilo mesmo que há nela" (BASTOS, 2013, p. 95). A partir de então, caminha por etapas.

Primeiramente atentaao fato de o conto ser escrito em primeira pessoa e constituir-se como rememoração do narrador de sua história familiar. O interlocutor, Ofélia, é um animal, uma cadela, deixando claro tal dado, conforme afirma o crítico, tratar-se de "um falso interlocutor, representando a impossibilidade de comunicação humana" (BASTOS, 2013, p. 100). As lembranças apresentadas pelo narrador, por sua vez, não são verídicas, uma vez que, ao final do conto, conforme destaca Hermenegildo Bastos, faz a seguinte colocação: "Mas gostaria tanto se aquele meu bisavô tivesse existido" (RUBIÃO, apud BASTOS, 2013, p. 98).O bisavô a que o narrador se refere, José Henrique Ruivães, foi capitão de navio negreiro. Seu avô não foi marinheiro por ter deixado de existir o tráfico de escravos. Seu pai jamais se manifestou em relação à "vocação ancestral". Todas as lembranças relatadas de maneira nostálgica são, no entanto, ficcionais.

Preocupado com "a história das relações humanas mediatizadas pelo dinheiro" (BASTOS, 2013, p. 98), o crítico atém-se à presença do mar no conto analisado como espaço de comércio, pois é vistopor sua utilização pelos navios negreiros. Ressalta ainda as tatuagens no corpo de Pedro, personagem lembrado pelo narrador, como "as marcas dos grilhões nos corpos dos escravos" (BASTOS, 2013, p. 103) e não como reminiscência de antigos amores, conforme registra o narrador.

Por aí segue o crítico, conduzindo o leitor à tomada de consciência de que está diante de devaneiosinofensivos do narrador, uma vez que fictícios. Acontece que como tais, fictícios, mostram-se "comprometidos com a história da violência e de horrores da colonização" (BASTOS, 2013, p. 105). Os devaneios são, em verdade, espectros, conforme presente no título do estudo de Hermenegildo Bastos, tratando-se o conto muriliano de "escrita fantasmagória" na qual a radicalização do insólito permite a insurgência do espectral de nossa história. 
O último estudo presente no livro foi escrito pela Profa. Dra. Viviane de Guanabara Mury, do Instituto Federal do Rio de Janeiro. Intitula-se "O duplo e algumas implicações para o fantástico em Murilo Rubião". O texto analisa a presença do duplo na obra de Rubião, onde a dualidade estudada pela autora trata da oposição natural versus antinatural. Para estabelecer sua análise, a autora divide a obra em duas categorias, uma ligada ao estra- nho (que não se relaciona àquele definido por Freud ou Todorov) e outra ao absurdo. Os contos definidos como estranhos são aqueles em que os personagens não apresentam espanto frente ao insólito. Relacionados ao absurdo, estão os contos onde os personagens percebem com assombro os fatos narrados que não deveriam ter acontecido, mas aconteceram. Para desenvolver sua reflexão acerca dessas categorias, a autora faz um recorte na obra de Rubião. Para tratar do estranho, analisa os contos "O pirotécnico Zacarias", "Teleco, o coelhinho" e "O ex-mágico da Taberna Minhota". Para comentar sobre o absurdo analisa o conto "A fila".

Ao analisar o conto "O pirotécnico Zacarias", destaca a passividade dos personagens frente ao evento insólito do morto que permanece com as características de vivo. A condição humana aparece como absurda e anormal. Há a possibilidade de uma existência correlata entre o natural e o antinatural. Em relação a "Teleco, o coelhinho" a autora aponta como cau- sador de estranheza não a atitude de Teleco (personagem antinatural, que sofre seguida mutações e não possui forma definida),mas a do personagem humano, portanto, natural, que o acolhe. A autora aponta a impossibilidade do personagem humano lidar com outros humanos. Sua relação com Teleco só é possível enquanto este permanece afastado de alguma forma próxima à humana. A autora também problematiza a condição do homem ao tratar da forma final de Teleco. O natural é apresentado como o hediondo. Há uma predicação pelo antinatural. Quando analisa o "O ex-mágico da Taber- na Minhota" situa o conto ao lado de "Teleco, o coelhinho". Aqui também é contestada a condição humana, elegendo o antinatural como ideal do personagem. Diferentemente do que ocorre em "O pirotécnico Zacarias", não há a possibilidade de coexistência sem choque do natural e do antinatural. 0 personagem também demonstra seu desprezo pelos homens, desejando criar um mundo completamente mágico, antinatural.

O conto "A fila", representante da categoria do absurdo, não apresenta nenhum elemento antinatural. Todos os fatos narrados são plausíveis e ocorrem em um cenário de pretensa normalidade. $O$ fato insólito é posto na atitude do personagem que se assombra frente à condição em que se 
encontra, enquanto todos os outros homens o consideram normal. A autora conclui que na obra de Rubião o insólito está sempre posto ao lado do natural e não do antinatural, como seria de se esperar. 0 estranho e 0 absurdo constituem a condição humana, onde o inaceitável é o natural.

O conjunto de textos apresentados nessa publicação atesta a riqueza de leituras e caminhos possíveis para o estudo da obra do autor. Ao tratar de diferentes aspectos, cada um dos críticos demonstra como a obra de Murilo Rubião, vinte anos depois de sua morte,apresenta-se tão pertinente e como a sua escrita trabalha no sentido de colocar a própria literatura em questão. 